livraisons

d'Histoire

de l'Architecture

\section{Livraisons de l'histoire de l'architecture}

$36 \mid 2018$

Jean-Louis Pascal (2)

\title{
Le restaurateur de la basilique Notre-Dame des Doms à Avignon
}

The restorer of the cathedral of Our Lady of Doms

Der Restaurator der Basilika Notre-Dame des Doms

\section{Anne Richard-Bazire}

\section{OpenEdition}

Journals

Édition électronique

URL : http://journals.openedition.org//ha/1031

DOI : 10.4000//ha. 1031

ISSN : 1960-5994

Éditeur

Association Livraisons d'histoire de l'architecture - LHA

Édition imprimée

Date de publication : 15 décembre 2018

Pagination : 77-101

ISSN : 1627-4970

Référence électronique

Anne Richard-Bazire, "Le restaurateur de la basilique Notre-Dame des Doms à Avignon ", Livraisons de I'histoire de l'architecture [En ligne], 36 | 2018, mis en ligne le 15 décembre 2020, consulté le 25 janvier 2021. URL : http://journals.openedition.org//ha/1031 ; DOI : https://doi.org/10.4000//ha.1031 


\title{
LE RESTAURATEUR DE LA BASILIQUE NOTRE-DAME DES DOMS À AVIGNON
}

\begin{abstract}
"L'insigne basilique, métropole de la province ordinaire, s'élève au nord du Palais des Papes, sur un rocher qui domine la ville entière, et le cours du Rhône. De larges perrons conduisent à l'église. Lorsqu'Avignon faisait partie des États Pontificaux, sa cathédrale était fameuse par la richesse de ses ornements, le luxe de ses sculptures, l'originalité de ses fresques ${ }^{1}$, la beauté de ses tableaux, le nombre et la splendeur de ses mausolées [...] L'édifice fut spolié et saccagé en 1793. Entreprise en 1819, interrompue par les évènements de 1830, la restauration de la cathédrale s'est achevée de nos jours " ${ }^{2}$.
\end{abstract}

Le 27 octobre 1888, Jean-Louis Pascal est nommé architecte du diocèse d'Avignon en remplacement d'Eugène Gustave Édouard Danjoy (1838-1905) lui-même nommé architecte diocésain d'Orléans et de Lille. À ce titre, Pascal avait en charge la basilique métropolitaine de Notre-Dame des Doms ${ }^{3}$ qui jouxte le Palais des Papes au nord, l'archevêché situé au $n^{0} 4$ de la rue de Mons ${ }^{4}$ dont les jardins s'étendaient alors jusqu'au flanc sud du Palais des Papes, et le grand séminaire Saint-Charlesde-la-Croix situé rue Saint-Charles. L'église métropolitaine, ou métropole, est la cathédrale d'un siège archiépiscopal ; Notre-Dame des Doms a été élevée à cette dignité, le 21 novembre 1475, à la suite de l'érection en archevêché de l'évêché d'Avignon par le cardinal Julien de la Rovère, nouvel évêque d'Avignon depuis le 23 mai 1474 et futur Jules II. Elle est par ailleurs "basilique mineure » depuis 1854, c'est-à-dire rattachée à l'une des grandes basiliques romaines, Sainte-Marie Majeure.

1. Le porche abritait deux fresques de Simone Martini, représentant l'une un Christ en majesté entouré d'anges, l'autre une Vierge à l'enfant, dans deux tympans triangulaire et semi-circulaire surplombant le portail d'entrée. Elles furent déposées dans la salle du Consistoire, au rez-de-chaussée de l'aile est du cloître de Benoît XII dans le Palais des Papes; elles datent des années 1340-1344.

2. B.n.F., dp. Mss., N.a.fr. 6095 : collection Guilhermy, Description des localités de la France, II : Anisy-Azy, volume de 399 feuillets cotés 419-818, 9 août 1886, folio 758.

3. "Doms" définirait la fonction de l'édifice : l'église de la maison de l'évêque ("De domo épiscopali »). Selon d'autres auteurs, il évoquerait sa fonction d'église-mère : "De domo ", c'est-à-dire "du dôme ». Il pourrait qualifier l'église des chanoines : «De domnis» (contraction de dominis), ou bien encore un lieu situé en hauteur, voire fortifié, l'église étant située au sommet du " rocher des Doms». Mgr André Reyne, abbé Daniel Brehier, La Métropole de Notre-Dame des Doms, haut lieu de spiritualité d'art et d'histoire, Lyon, s.d., p. 7-12 et 85-87.

4. Au XV e siècle, cette rue s'appelait rue de la Vice-Gérence; en 1795, elle devient rue Cardinale. C'est l'actuelle rue de Mons. Joseph Girard, Évocation du vieil Avignon, Paris, les éd. de Minuit, 1958, p. 175. L'évêché fait face à l'hôtel de ville d'Avignon, par-delà la place de l'horloge. 


\section{Un édifice en déshérence}

La position de la cathédrale au point le plus élevé de la ville (ill. 1) en rendait l'accès souvent pénible: "La métropole d'Avignon qui s'élève à l'extrémité de la ville sur un rocher escarpé n'est guère qu'une chapelle dans ses proportions. L'abord en est très difficile et parfois dangereux sous le souffle impétueux de notre mistral. " outre le fait que celle-ci fut ruinée à la Révolution française, et mise "absolument hors de service ", c'est sans doute une des raisons qui lui fit perdre son titre de cathédrale $^{6}$ au bénéfice de la collégiale Saint-Agricol située dans la ville basse ${ }^{7}$. Notre-Dame des Doms ne fut plus alors qu'un but de pèlerinage lors des processions des grandes fêtes solennelles jusqu'en 1822, date à laquelle une ordonnance de Louis XVIII remet la métropole à la disposition de l'archevêque ${ }^{8}$; c'est le début de sa renaissance. L'ordonnance royale du 3 mars 1836 transfere définitivement le siège de l'archevêque, de Saint-Agricol à Notre-Dame des Doms. C'est grâce aux soins et aux dons de l'archevêque Jacques Marie Antoine Célestin Dupont (1792-1859), nommé à Avignon en $1835^{\circ}$, que la restauration de la cathédrale commence. Mais l'église n'étant pas une paroisse de ville, et étant peu fréquentée à cause de sa position excentrée, ne dispose alors que de peu de ressources.

À son arrivée à Avignon en 1848, l'archevêque Jean-Marie Mathias Debelay (1800-1863) ${ }^{10}$ trouve l'édifice dans un état déplorable :

" En dehors du chapitre métropolitain, aucune obligation religieuse n'y attire les fidèles, puisqu'elle n'est pas érigée en paroisse et lorsqu'une solennité religieuse m'appelle à officier pontificalement à la métropole, [...] nous ne pouvons recevoir sous ses nefs plus d'un vingtième de la population qui désirerait y trouver place. [...] Aussi ai-je trouvé à mon arrivée à Avignon les vases sacrés de la métropole au Mont-de-Piété et c'est à une bourse qu'ils doivent d'en être sortis. Aussi sur trois cloches que possède la métropole, deux sont fendues et partant restées muettes depuis $1830 »^{11}$.

C'est aussi l'avis de l'inspecteur général Léon Vaudoyer qui visite l'édifice en 1853, alors que l'architecte diocésain est Joseph Auguste Joffroy:

5. Arch. nat., $\mathrm{F}^{19} 7625$, lettre de l'archevêque d'Avignon, Jean-Marie-Mathias Debelay, au ministre de l'instruction publique et des cultes, 31 octobre 1852.

6. Le 29 août 1793, Simon Stylite François Rovère, élu évêque constitutionnel du Vaucluse, fait de Saint-Agricol sa cathédrale.

7. Arch. nat., $\mathrm{F}^{19} 7222$, rapport de l'inspecteur général Lasteyrie sur la cathédrale Notre-Dame des Doms, diocèse d'Avignon, août 1840, p. 1.

8. L'archevêque est alors Étienne Parfait Martin Maurel de Mons, né à Aix le 17 août 1752, évêque de Mende en 1805, archevêque d'Avignon en 1821, pair de France sous Charles X et décédé à Avignon le 6 octobre 1830 ; à la même époque, on rétablit le grand séminaire à Saint-Charles (en 1824) et on installe le petit séminaire au Petit Palais, archevêché sous l'ancien régime.

9. Il le sera jusqu'en 1842 ; lui succède Mgr Paul Naudo, de 1842 à 1848.

10. Archevêque d'Avignon de 1848 à 1863.

11. Arch. nat., $\mathrm{F}^{19} 7625$, lettre de l'archevêque d'Avignon, Jean-Marie-Mathias Debelay, au ministre de l'instruction publique et des cultes, 31 octobre 1852 . 


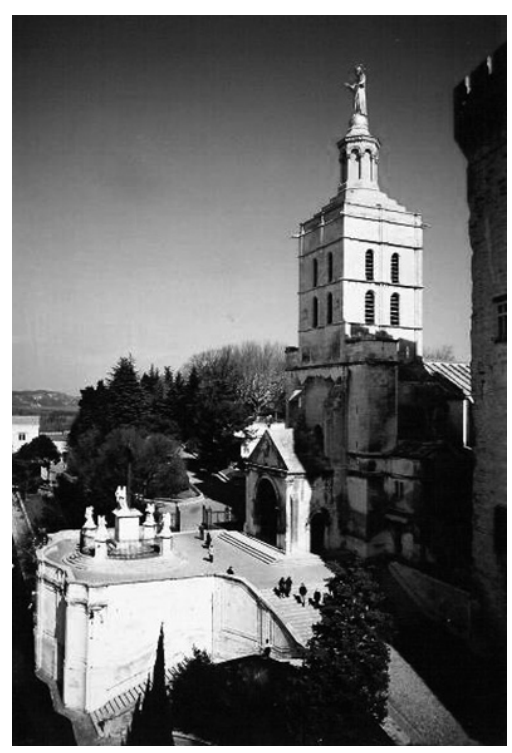

Ill. 1 : Basilique Notre-Dame des Doms située au nord du Palais des Papes à Avignon, avec la vue sur l'escalier du Pater et la plateforme du calvaire. La majeure partie de l'église appartient au style roman $\mathrm{du} \mathrm{XII}^{\mathrm{e}}$ siècle. Le chœur a été agrandi au XVII ${ }^{\mathrm{e}}$ siècle et des chapelles latérales ajoutées du $\mathrm{XIV}^{\mathrm{e}}$ au $\mathrm{XVII}^{\mathrm{e}}$ siècle. Cl. auteur.

"L'église de Notre-Dame des Doms [...] est sans contredit l'un des monuments les plus intéressants du midi. [...] Son porche [...] offre au premier abord toutes les caractéristiques d'une construction romaine du Bas-Empire [...] Si cette église s'était conservée telle qu'elle était primitivement, c'eût été un enseignement des plus précieux pour les architectes et les artistes mais elle a été tellement défigurée qu'il faut aujourd'hui de grands efforts pour en retrouver l'ensemble complet et recomposer par l'imaginaire l'église originaire, tant il semble qu'on ait pris à tâche de la faire disparaître au milieu des constructions de toutes formes et de tous styles, sans considération aucune pour la valeur de l'édifice aussi indignement déshonoré. Cet état de choses est des plus regrettables [...] il ne peut être aujourd'hui modifié qu'en se décidant à prendre un parti radical, fort désiré par Mgr l'archevêque mais que je n'ose moi-même proposer ; ce serait la construction d'une cathédrale neuve [...] la cathédrale d'Avignon est un de ces monuments dans lesquels il faut faire très peu ou beaucoup ${ }^{12}$.

La majeure partie de l'église appartient au style roman du XII ${ }^{\mathrm{e}}$ siècle $^{13}$. Le chœur a été agrandi au XVII ${ }^{\mathrm{e}}$ siècle et des chapelles latérales ajoutées du XIV ${ }^{\mathrm{e}}$ au

12. Arch. nat., $\mathrm{F}^{19} 1823$, rapport de l'inspecteur général des édifices diocésains, Léon Vaudoyer, diocèse d'Avignon, cathédrale Notre-Dame des Doms, 1853, p. 95-103.

13. «La simplicité de la forme primitive et de la décoration, le plein cintre de toutes les fenêtres et de la plupart des voûtes, sont des caractères auxquels il est facile de reconnaître la période romane ". Arch. nat., $F^{19}$ 7222, rapport de l’inspecteur général Lasteyrie sur Avignon, août 1840, p. 3. 


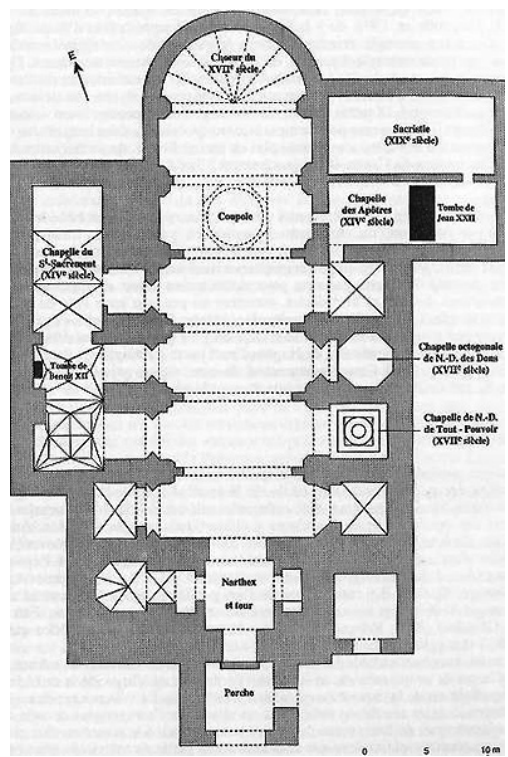

Ill. 2 : Plan de la basilique Notre-Dame des Doms à Avignon. Michel Chevalier, La France des cathédrales, du IV eu XX'e siècle, Rennes, éd. Ouest France, 1997, p. 130.

XVII ${ }^{e}$ siècle. Surplombant le narthex que précède un porche, un grand clocher carré (ill. 1), qui devait présenter une silhouette voisine de celui de la cathédrale Saint-Trophime d'Arles, à deux ou trois étages en retrait les uns par rapport aux autres avec un couronnement pyramidal, fut endommagé lors des luttes du grand schisme et reconstruit à partir du premier étage au $\mathrm{XV}^{\mathrm{e}}$ siècle. Il est surmonté d'une vierge monumentale depuis 1859 . La nef présente quatre travées avec chapelles sans collatéraux (ill. 2). La reconstruction de l'abside et l'édification de tribunes au $\mathrm{XVII}^{\mathrm{e}}$ siècle ont quelque peu altéré le caractère roman de l'édifice, que conserve néanmoins la coupole qui domine la croisée du transept (ill. 3). Aussi lorsque l'on décide de refaire les cinq verrières du chœur, Prosper Renaux (1793-1852), architecte diocésain d'Avignon depuis 1849 va proposer de modifier les cinq fenêtres ${ }^{14}$ pour leur redonner un caractère roman, en analogie avec les ouvertures de la coupole $^{15}$. On a affaire, notamment à partir de la monarchie de Juillet, à " des architectes appartenant à un cadre administratif, et surtout, remplis d'un savoir archéologique plus ou moins sûr [dont l'] ambition est de refaire l'œuvre dégradée ou mutilée des maittres médiévaux, souvent même de la surpasser, au besoin en détruisant les parties qu'ils jugent contraires au style de l'époque principale de

14. Les cinq croisées en plein cintre mesuraient : 3,66 m sur 1,11 m. La croisée du milieu, murée, était masquée par un tableau. Les quatre autres étaient pourvues de châssis en bois de noyer enserrant des carreaux de vitre ordinaire. La fabrique demandait des vitraux colorés et des châssis métalliques.

15. Arch. nat., $F^{19}$ 7625, lettre au préfet du directeur des cultes, datée du 17 juin 1850, reprenant le devis de Renaux concernant les travaux à exécuter dans la cathédrale en 1850. 


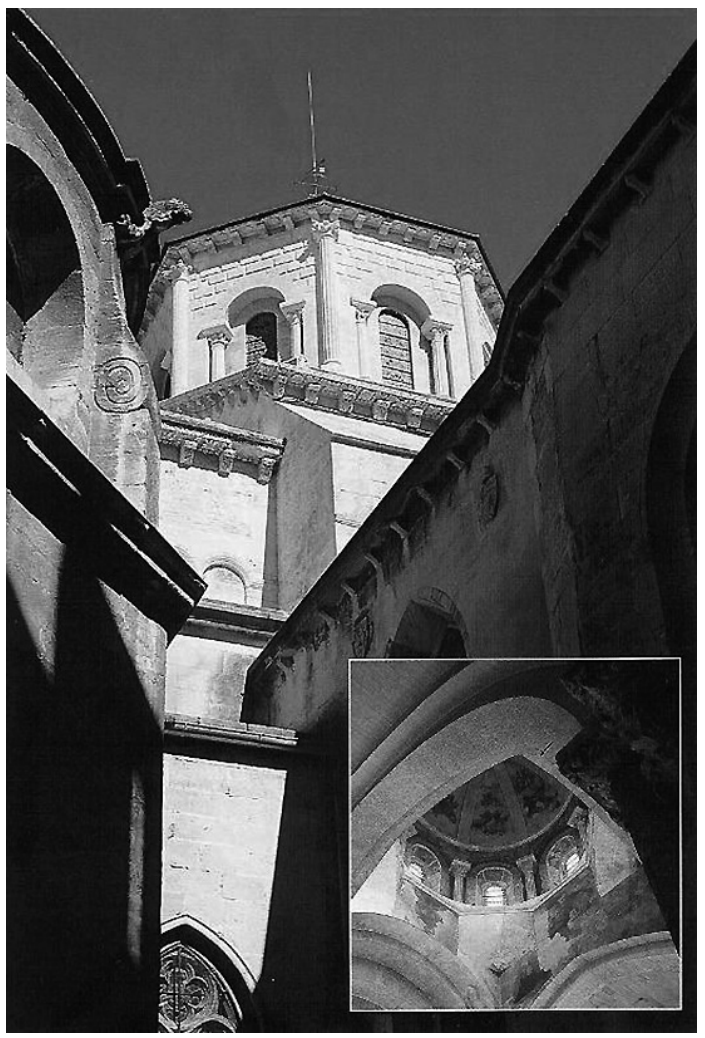

Ill. 3 : Basilique Notre-Dame des Doms, Avignon. Vue extérieure du lanternon, situé à la croisée du transept, qui a conservé son caractère roman; le dôme est recouvert de cuivre. Vue intérieure de la coupole qui domine la croisée du transept. Mgr André Reyne, abbé Daniel Brehier, La Métropole Notre-Dame des Doms, haut lieu de spiritualité, d'art et d'histoire, Lyon, Art et Tradition, s. d., p. 256.

construction. " ${ }^{16} \mathrm{La}$ "logique des dominos ", selon l'expression de Jean-Michel Leniaud, conduit ainsi, de fil en aiguille, à reconstruire la totalité d'un édifice, de façon irréversible. Henri Labrouste, inspecteur des travaux, fait alors, au nom de l'architecte diocésain empêché, un rapport à la commission des édifices religieux : " Il y a tant de choses disparates dans cette église que je ne vois pas l'utilité de refaire des fenêtres d'un style roman dans ce chœur du XVII ${ }^{\mathrm{e}}$ siècle " ${ }^{17}$.

La croisée du milieu fut démurée, on y plaça un vitrail représentant l'Assomption de la Vierge accompagnée d'un groupe d'anges. Les croisées de droite et de gauche représentaient saint Ruf et saint Agricol, les deux extrêmes, sainte Martre et sainte

16. Michel Chevalier, La France des cathédrales, du $I V^{e}$ au $X X^{e}$ siècle, Rennes, éd. Ouest France, 1997 , p. 265.

17. Arch. nat., F 19 7625, rapport d'Henri Labrouste à la commission des édifices religieux, 16 mai 1850 . 


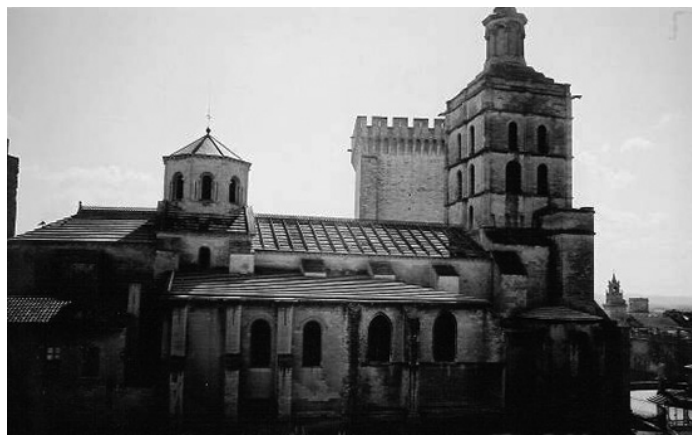

Ill. 4 : Vue du bas-côté nord de la basilique Notre-Dame des Doms à Avignon. Cl. auteur.

Anne. Toutes ces figures étaient « de grandeur colossale [...] peintes sur fond d'azur et accompagnées d'ornements d'architecture colonnelés et arcades de style roman [...] dans le bas un cartouche avec le nom ou les attributs du personnage, saint Agricol avec une cigogne dévorant un serpent; dans le cartouche du milieu les armoiries de la ville, etc. ${ }^{18}$. Quatre statues de marbre, celles de Constantin et de Charlemagne destinées à remplir deux niches vides dans l'abside, et celles de saint Pierre et saint Paul destinées à la façade de l'église, sont commandées à Titus Ristori, statuaire napolitain domicilié à Avignon et filleul de la reine Marie-Amélie.

Tout l'édifice est recouvert de dalles, même les chapelles, à l'exception du dôme recouvert de cuivre (ill. 4). Léon Vaudoyer avait proposé en 1853 le remaniement total de la couverture en pierre de la nef, la réfection du comble de la chapelle du Saint-Sacrement ${ }^{19}$ et plus généralement la reprise de toutes les toitures dont «la détérioration est conséquence de la négligence qu'on a mise à les entretenir » ${ }^{20}$.

"J'estime, en conséquence, [continuait Vaudoyer dans son rapport...] que l'architecte actuel [Joffroy] ne paraissant pas comprendre suffisamment l'intérêt qui s'attache à cet édifice, il convient d'attendre qu'un nouvel architecte plus capable ou au moins plus zélé soit invité à étudier sérieusement les véritables besoins de ce monument [...] Mais de tous les griefs qui peuvent être imputés à l'architecte de la cathédrale d'Avignon, il en est un que je ne saurais passer sous silence ; c'est celui d'avoir laissé disparaitre les admirables fresques attribuées au Giotto ${ }^{21}$, qui décoraient le porche, car il est parfaitement démontré que ces fresques, exécutées sur un enduit qui s'est détaché petit à petit du mur, auraient pu facilement être sauvées d'une ruine complète. Combien n'est-il pas coupable l'architecte qui, préposé à la garde et

18. Ibid., devis descriptif et estimatif des vitraux coloriés qu'on se propose de placer dans les cinq ouvertures du chœur de l'église, rédigé le $1^{\text {er }}$ juin 1846 par l'architecte du département Renaux.

19. Première chapelle du bas-côté gauche vers le chœur.

20. Arch. nat., $\mathrm{F}^{19} 1823$, rapport de l'inspecteur général des édifices diocésains, Léon Vaudoyer, op. cit., p. 97.

21. Attribuées désormais à Simone Martini (circa 1284-1344). 
à l'entretien d'un édifice aussi intéressant, est assez négligent pour laisser périr de semblables trésors ${ }^{22}$."

Joseph Joffroy était peu apprécié de l'administration centrale qui chercha à le remplacer en 1853, mais il était soutenu par les autorités locales, préfet et archevêque. Il ne sera remplacé qu'en 1879 par Eugène Danjoy (1838-1905).

Dans un premier temps, Pascal s'occupe de la reprise des dallages dans le porche, la nef et la première chapelle latérale côté nord; il y remplace les dalles usées ou brisées par de la pierre de Saint-Rémy ou de Caromb ${ }^{23}$. Il renouvelle les menuiseries des portes et fenêtres en mauvais état sur les façades de la contre-tour sud, répare la toiture et les parements des murs au-dessous ${ }^{24}$. Par la suite, il répare le contrefort nord de la tour du campanile et les parements au-dessus ${ }^{25}$. Il reprend enfin les anciens contreforts et les parements des murs (façades nord et est) et répare les gouttières et tuyaux de descente des eaux pluviales dans la cour à l'est de la cathédrale (dite de la maîtrise) dont il restaure le mur de clôture, et sur la rue Cardinale ${ }^{26}$.

\section{L'ouvre de Jean-Louis Pascal à l'extérieur de la cathédrale}

\section{L'escalier du Pater, la plateforme du calvaire et les murs de soutènement de la cathédrale}

"Très tôt, il semble y avoir eu une plateforme devant le porche de la cathédrale, avec un chemin en pente douce à gauche et à droite d'un mur de soutènement de cette plateforme. Ce lieu était idéal pour les manifestations publiques et officielles de la commune [...] On attribue au cardinal Pierre de Foix la reconstruction en 1434, du parvis et des escaliers permettant d'y

22. Arch. nat., $\mathrm{F}^{19} 1823$, rapport de l’inspecteur général des édifices diocésains, Léon Vaudoyer, op. cit., p. 98-99.

23. Arch. nat., $\mathrm{F}^{19}$ 7626, devis du 29 décembre 1888 de Pascal envoyé au préfet du Vaucluse puis devis du 30 décembre 1901, du 5 décembre 1903, du $1^{\text {er }}$ décembre 1904 de Pascal au préfet du Vaucluse, F 19 7627, dans lesquels il demande toujours des crédits pour entretenir les dallages intérieurs de la cathédrale. En 1888, l'entrepreneur de maçonnerie François Chanoux est chargé de l'entretien des dallages de la nef comme des chapelles. Arch. dép. du Vaucluse, 3V8; 3V9.

24. Arch. dép. du Vaucluse, 3V9, devis descriptif et estimatif des travaux d'entretien à exécuter en 1890, Pascal, 15 novembre 1889. Les travaux s'élèvent à 3787,90 francs. La soumission de François Chanoux du 11 février 1890 est acceptée le 21 mars 1890.

25. Ibid., deux devis de l'architecte Louis Valentin, inspecteur des travaux d'Avignon depuis 1879 , datés du 15 novembre 1895 et du 5 décembre 1896. La soumission de Bernard Laurent datée du 5 mai 1897 est approuvée pour les travaux d'entretien à la cathédrale et à l'archevêché pour 6500 francs.

26. Ibid., devis descriptif et estimatif des travaux d'entretien à exécuter en 1900, Pascal, 30 novembre 1899. 
accéder plus aisément. Cet escalier fut appelé "escalier du Pater" car il comptait autant de marches que de mots dans la prière du Notre-Père ${ }^{27}$. "

Le dégagement devant la cathédrale se révélant trop exigu, celui-ci fut agrandi au milieu du XVIII e siècle par l'architecte avignonnais Jean-Baptiste Franque (1683-1758), d'après les plans de l'architecte et sculpteur Jean-Baptiste Béru (ill. 1). Un mur en pierre de Villeneuve et une terrasse avec son escalier furent construits en avant de l'ancienne plateforme dont le niveau fut abaissé au niveau de la nouvelle. Cet aménagement avait pour but de soutenir les terres d'un chemin que les chanoines voulaient réaménager pour faciliter l'arrivée des carrosses et autre voitures. Le parapet de la terrasse devait être en pierre de Villeneuve avec couverture en pierre d'Oppède ${ }^{28}$. Cet ensemble, que nous voyons encore aujourd'hui, fut financé par les chanoines de la Métropole. Le mur principal soutenant la plateforme est à panneaux-pilastres, bossages et cordons (ill. 5). Un grand calvaire, érigé en 1819 au centre de la plateforme par le sculpteur Joseph Baussan de Caderousse, représente le Christ en croix, la Vierge, saint Jean, et quatre anges adorateurs sur leur socle ; le calvaire est entouré d'une grille de protection. Restauré à de nombreuses reprises, le Christ fut déposé en 1993 dans la Métropole et remplacé par une copie ${ }^{29}$.

Les travaux effectués sous la direction de Jean-Louis Pascal en 1890-1891 concernent la réfection du pavage ${ }^{30}$ de la plate-forme du calvaire de la cathédrale d'Avignon $^{31}$. En 1891, l'architecte fait établir un dallage imperméable préservant le terre-plein de l'infiltration des eaux pluviales et il prévoit la réparation des murs de soutènement de l'escalier du côté de la place du Palais des Papes, et des reprises dans la partie supérieure des murs en retour, côté nord et côté de l'escalier au $\operatorname{sud}^{32}$. En effet, les parements sont en très mauvais état, les matériaux corrodés en

27. Mgr André Reyne, abbé Daniel Brehier, La Métropole de Notre-Dame des Doms, haut lieu de spiritualité d'art et d'histoire, op. cit., p. 128.

28. Ibid., p. 129.

29. Ibid., p. 130-132. Il semble que le Christ original ait été déposé derrière l'autel de la chapelle Spiéfami ( $1^{\text {re }}$ chapelle bas-côté gauche) et remplacé. En 1993, la Direction régionale des affaires culturelles a décidé la restauration complète de la croix et du Christ ; ce dernier, consolidé par les ateliers Mérindol, a été mis à l'abri dans la tribune de la Métropole et remplacé par une réplique sculptée. À la demande de la Direction Régionale des Affaires Culturelles, l'emmarchement du calvaire a été repris en octobre 1999 par l'entreprise Martin d'Avignon.

30. Le pavage est réalisé en moellons (des carrières de Voguë dans l'Ardèche) smillés avec ciselure sur les arêtes, posés au mortier hydraulique ; les pavés ont une largeur uniforme de 0,25 m, les longueurs varient de 0,35 à $0,45 \mathrm{~m}$, les ciselures ont $0,025 \mathrm{~m}$ de largeur. Pour remplacer la $1^{\text {re }}$ marche du Pater, Pascal utilise la pierre de taille de Caromb. La soumission d'Henri Souvet s'élevant à 9 615,62 francs est acceptée le 11 septembre 1890. Arch. dép. du Vaucluse, 3V8, dossier : pavage de la plate-forme du calvaire, 1890-1891.

31. Arch. nat., F 19 7627, lettre du 4 août 1891 du préfet du Vaucluse au ministre de la justice et des cultes.

32. Ibid., devis estimatif des travaux de grosses réparations à exécuter en 1893, Jean-Louis Pascal, 15 juin 1892. 


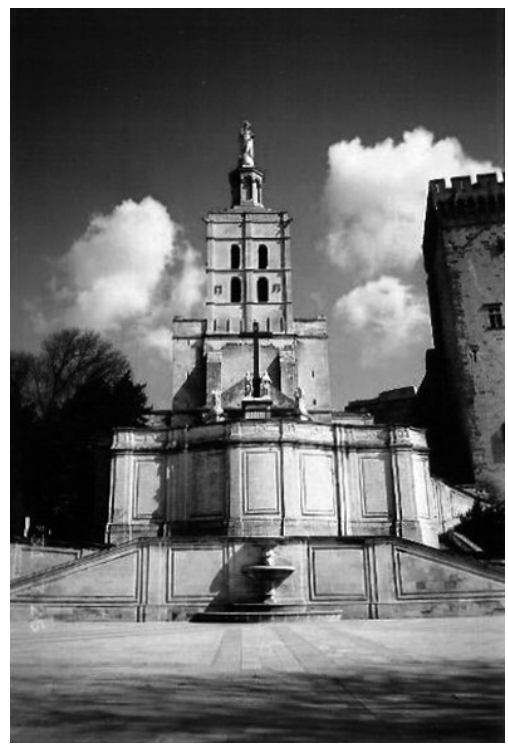

Ill. 5 : Dégagement devant la cathédrale Notre-Dame des Doms. Celui-ci fut agrandi au milieu du XVIII ${ }^{\mathrm{e}}$ siècle par l'architecte avignonnais Jean-Baptiste Franque, d'après les plans de l'architecte et sculpteur Jean-Baptiste Béru. En 1891, Jean-Louis Pascal fait établir un dallage imperméable préservant le terre-plein du Pater de l'infiltration des eaux pluviales. Les travaux s'achèvent en 1894 par la restauration de la façade principale du mur de soutènement de l'escalier du Pater. Cl. auteur.

grande partie sont à reprendre en sous-œuvre par portions sur la façade principale et une partie des murs en retour. L'entrepreneur de travaux publics avignonnais Henri Laurent Souvet s'engage à exécuter les travaux en 1893 pour 12 305,92 francs $^{33}$. Les travaux s'achèvent en 1894 par la restauration de la façade principale du mur de soutènement de l'escalier du Pater ${ }^{34}$.

Les années 1895-1897 voient les travaux de réparation des murs de soutènement des terrains dépendant de la cathédrale à l'est. C'est encore l'entrepreneur Henri Laurent Souvet qui s'en charge comme de tous les travaux d'entretien de la métropole ${ }^{35}$.

33. Arch. dép. du Vaucluse, 3V8, dossier : restauration des murs de soutènement de la terrasse du Pater, 15 juillet 1893.

34. Le devis estimatif des travaux de grosses réparations à exécuter en 1894 fait état de $10312,50 \mathrm{fr}$., ibid., devis de Pascal du 30 novembre 1893. La soumission de Souvet qui s'engage à exécuter les travaux pour 9500 fr., datée du 3 février 1894, est acceptée le 22 février 1894.

35. Henri Souvet et fils, 52 rue Thiers, Avignon, est remplacé en 1902 par Bernard Laurent, entrepreneur en maçonnerie, 38 rue du Rempart du Rhône, Avignon, puis en 1905 par son fils Philippe Laurent. 


\section{Le porche}

"Profond de plus de sept mètres, haut de plus de douze mètres, avec des murs de deux mètres dix d'épaisseur, large intérieurement de huit mètres, il s'ouvre comme un arc de triomphe sur l'entrée principale de l'église " ${ }^{36}$ (ill. 6). Ajout de la seconde moitié du XII e siècle à la cathédrale romane, il constitue un puissant soutènement à la masse du clocher qui domine l'entrée. Un toit en dalles de pierre à deux rampants s'achève au-dessus de l'entrée par un fronton triangulaire percé d'un oculus ; l'entablement, à la corniche à modillons ornée d'une frise de grecques, est supporté par deux colonnes cannelées engagées, à chapiteaux corinthiens, posées sur un piédestal. Cet ensemble encadre le grand arc d'ouverture ouest en plein cintre, dont les claveaux sont bordés par une archivolte à rang de perles et pirouettes, oves et fer de lance. Le porche était muni de grilles au début du XVIII siècle ; Charles Giraud, serrurier d'Avignon avait, à la demande du chapitre, réalisé en 1719 une grille à deux portes avec décor d'anses de panier, fleur de lys, liens à cordons, flammes et feuilles d'eau. Elle n'existait plus à la fin du XIX ${ }^{\mathrm{e}}$ siècle. Pour clôturer le porche précédant l'entrée principale de la cathédrale, Jean-Louis Pascal demande la construction d'une grille en fer forgé destinée à protéger celui-ci, trop souvent transformé en dépôt d'immondices ${ }^{37}$. La grille fut réalisée par le serrurier avignonnais Antoine Audemard ${ }^{38}$.

\section{Le campanile}

Du sol jusqu'au socle de la statue qui le surmonte, le campanile mesure 39,40 mètres. Il est situé immédiatement au-dessus du portail et du porche roman, disposition relativement rare mais qui peut s'expliquer par la situation de la ville resserrée au pied du rocher côté ouest. Du clocher primitif, il ne reste que les bases, la souche englobant l'entrée, et une partie de l'élévation signalée par des demicolonnes à fût lisse à la base de l'actuelle construction. Il y en avait six sur chacune des faces du clocher, avec trois pilastres cannelés dont il subsiste les bases au centre et aux angles de chaque face ${ }^{39}$. Ces colonnes supportaient des arcatures comme l'on voit encore à Saint-Trophime d'Arles, sous de fortes corniches soulignant chaque

36. Mgr André Reyne, abbé Daniel Brehier, La Métropole de Notre-Dame des Doms, haut lieu de spiritualité d'art et d'histoire, op. cit., p. 157.

37. Arch. nat., F ${ }^{19}$ 7627. Dans une lettre du 22 février 1896 de l'archevêché d'Avignon, le vicaire général Redon demande "l'établissement de deux grilles, qui interdiront pendant la nuit, l'accès du porche de la métropole aux mendiants et aux vagabonds, qui dégradent et salissent cette partie la plus antique et la plus intéressante de ce monument ", et rapport de Émile Vaudremer, inspecteur général, 23 novembre 1898 .

38. Antoine Audemard habite 25 rue de la Masse à Avignon. Le préfet approuve la soumission d'Audemard le 25 novembre 1903 ; ce dernier s'engage "à exécuter une grille et porte en fer forgé pour clôturer le porche précédant l'entrée principale de la cathédrale d'Avignon portées au devis et s'élevant à la somme de 3279,89 fr. moyennant un rabais de 15 fr./100 fr. sur le dit devis. ", Arch. du Vaucluse, 3V8.

39. Mgr André Reyne, abbé Daniel Brehier, La Métropole de Notre-Dame des Doms, haut lieu de spiritualité d'art et d'histoire, op. cit., p. 133. 


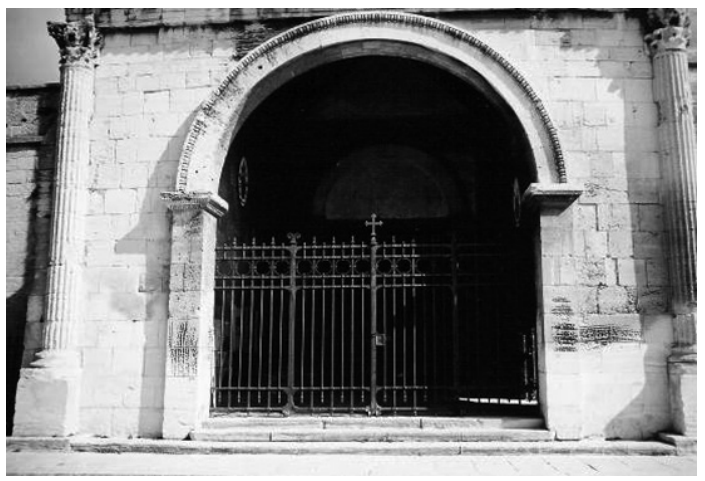

Ill. 6: Porche de la basilique Notre-Dame des Doms, ajout de la seconde moitié du XII siècle à la cathédrale. C'est Jean-Louis Pascal qui fait ajouter la grille, réalisée par le serrurier avignonnais Antoine Audemard, destinée à préserver l'entrée de l'édifice. Cl. auteur.

niveau en retrait. Ce clocher était flanqué de tourelles permettant par un escalier à vis d'accéder du premier au second étage, épaulé à l'ouest par deux contreforts.

À la suite des destructions dues aux deux sièges ${ }^{40}$ dont Notre-Dame des Doms fut l'objet sous le pontificat de Benoît XIII (1394-1423), le clocher fut reconstruit à deux niveaux seulement, percés de deux croisées sur les quatre faces. La Révolution et les trente années qui suivirent laissèrent une église à l'abandon. La restitution de son rôle de métropole au début du siècle entraîna un regain d'intérêt pour NotreDame des Doms et en 1827, le clocher fut réparé ; il est à nouveau endommagé par la foudre en 1859. Lorsque Jean-Louis Pascal arrive à Avignon, les abat-sons placés aux ouvertures de la tour du campanile n'existent plus qu'en partie. Ils laissent les eaux pluviales pénétrer à l'intérieur de la tour jusqu'aux charpentes du beffroi ${ }^{41}$. L'architecte diocésain demande de substituer des dalles en ardoise, au bois et au plomb initialement prévus ${ }^{42}:$ "L'église de Fourvière à Lyon est pourvue d'abat-sons

40. Septembre-novembre 1398 et mai 1410 - novembre 1411.

41. Le beffroi est le terme usuel désignant le dispositif de charpente où sont installées les cloches. Il porte remède à l'ébranlement de la maçonnerie qui pourrait être causé par les cloches sonnant à la volée, si elles étaient directement en contact avec elle, dans les ouvertures du clocher. Le beffroi du clocher de Notre-Dame des Doms en occupe toute la hauteur, à partir du premier étage jusqu'au sommet. Il est fait de poutres de chêne à croisillons chevillés pour la partie inférieure qui paraît contemporaine de la reconstruction du clocher, dans la première moitié du XVe siècle. Ce beffroi fut repris en juillet 1854 et consolidé en 1861 par Sébastien Gilles fils, entrepreneur de maçonnerie à Avignon, sur les plans de l'architecte diocésain Joffroy qui avait constaté des oscillations préoccupantes quand les neuf cloches du carillon sonnaient à la volée. Arch. dép. du Vaucluse, 3V8, cité par Mgr André Reyne, abbé Daniel Brehier, La Métropole de Notre-Dame des Doms, haut lieu de spiritualité d'art et d'histoire, op. cit., p. 139.

42. "Les abat-sons placés aux ouvertures de la tour du campanile, n'existent plus qu'en partie, une moitié environ manque et ce qui reste actuellement est dans un tel état de vétusté qu'une réfection complète est devenue nécessaire. L'insuffisance et le mauvais état des abat-sons actuels laissent les eaux pluviales pénétrer à l'intérieur de la tour jusqu'aux charpentes du beffroi et occasionnent des dégradations qui pourraient devenir importantes". 
en ardoise, une petite église à Croissy près de Paris aussi. Dans les deux cas, les baies sont d'une dimension assez rapprochée des arcades du clocher d'Avignon ${ }^{43}$. C'est Charles Fouinat ${ }^{44}$, représentant des ardoisières d'Angers, qui réalise le travail pour 4 355,96 francs ${ }^{45}$. Après avoir réparé le contrefort nord de la tour du campanile et refait les parements situés au-dessus ${ }^{46}$, Pascal poursuit, en 1904, la réparation des contre-tours du campanile ${ }^{47}$.

\section{La Vierge colossale de Notre-Dame des Doms}

Par lettre pastorale du 7 juin 1855, Mgr Debelay annonçait le projet d'ériger une statue de la Vierge sur le clocher de la Métropole (ill. 7). La promulgation du dogme de l'Immaculée Conception le 8 décembre 1854 et la protection demandée à la Vierge pour la ville décimée par le choléra en constituaient les principales raisons. Cette statue de la Vierge étendant les bras sur la ville dans un geste de protection devait mesurer huit mètres de haut et s'élever, grâce à un dôme et à une lanterne ronde, de dix mètres au-dessus de la tour. Elle fut mise au concours, remporté par le sculpteur avignonnais Joseph Étienne Napoléon Cournaud ${ }^{48}$ (1807-1863), et Joseph Auguste Joffroy, architecte départemental et diocésain, dressa les plans du piédestal. L'architecte essuya plusieurs refus de la part de l'inspecteur général Léon Vaudoyer. Celui-ci jugea le premier projet de piédestal en forme de dôme carré, disproportionné par rapport au reste de la tour, et ne mettant pas assez en valeur la statue qu'il voulait monumentale; Vaudoyer proposa pour le piédestal un octogone formé de huit colonnettes portant huit arcatures. Il s'opposa d'autre part à une statue de pierre armée de fer, offrant peu de chance de durer. Il lui préférait un matériau différent de celui de l'édifice et susceptible d'être vu de loin, comme le bronze doré ${ }^{49}$. Joffroy proposa un deuxième projet de piédestal ; Léon Vaudoyer le jugea « trop mesquin comme largeur et comme hauteur pour se lier convenablement avec la partie sur laquelle il porte ». L'inspecteur trouva d'autre part les tirants

Le devis fait état de : travaux : 4911,85 fr., imprévus : 88,15 fr., sous-total : 5 000,00 fr., honoraires : 375 fr., total : 5375 fr. Arch. dép. du Vaucluse, 3V8, devis de Pascal du 27 novembre 1893.

Aussi : Arch. nat., F 19 7627, lettre de Jean-Louis Pascal au préfet du Vaucluse, le 26 novembre 1893 puis lettre du ministre de l'instruction publique et des cultes au préfet du Vaucluse, le 9 décembre 1893 .

43. Arch. nat., F 19 7627, lettre de Jean-Louis Pascal au directeur des cultes, 17 octobre 1893.

44. 170 quai de Jemmapes, Paris.

45. Arch. dép. du Vaucluse, 3V8, dossier : remplacement des abat-sons du campanile, soumission du 28 novembre 1893 approuvée par le préfet le 8 janvier 1894.

46. Arch. nat., $\mathrm{F}^{19}$ 7627, devis descriptif et estimatif des travaux d'entretien à exécuter en 1897 , JeanLouis Pascal, 17 décembre 1896.

47. Ibid., devis du $1^{\text {er }}$ décembre 1904 de Jean-Louis Pascal au préfet du Vaucluse.

48. Né à Avignon, il travailla surtout dans sa ville natale. Il est l'auteur d'une pieta en pierre placée à l'église Saint-Didier. Le musée Calvet possède de lui la maquette de ce groupe et une esquisse en plâtre représentant sainte Madeleine. Stanislas Lami, Dictionnaire des sculpteurs de l'École Française au XIX eiècle, Paris, éd. Honoré Champion, 1916, vol. 1, p. 438.

49. Arch. nat., F 19 7627, rapport fait au comité des inspecteurs généraux des édifices diocésains. Séance du 7 juin 1856. Rapporteur : Léon Vaudoyer, inspecteur général. 


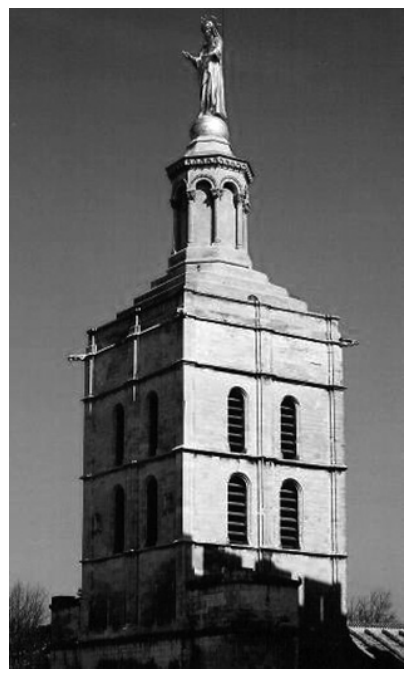

Ill. 7 : Basilique Notre-Dame des Doms, Avignon. Vue du clocher et de la Vierge monumentale érigée en 1859. Statue de plomb fondue par la maison Durand, de Paris, sur une maquette réalisée par le sculpteur Alexis Hippolyte Fromanger. Cl. auteur.

de fer, destinés à maintenir l'écartement des murs de la tour, mal placés par l'architecte diocésain ${ }^{50}$.

Autorisation fut enfin donnée pour une statue de plomb qui fut fondue par la maison Durand, de Paris, sur une maquette réalisée par Alexis Hippolyte Fromanger ${ }^{51}$ (1805-1892). Elle fut érigée le 25 août 1859 sur un piédestal octogonal de style roman à arcatures aveugles dont Léon Vaudoyer avait donné le dessin. D’une hauteur de treize mètres, il était posé sur des gradins à trois degrés; le tout reposait sur une voûte établie sur les dalles du toit-terrasse du $\mathrm{XV}^{\mathrm{e}}$ siècle. Le piédestal fut réalisé par les entrepreneurs Gilles et Bérard. La dorure fit l'objet à l'époque de débats. L'érection de cette statue correspondait à l'engouement du XIX ${ }^{\mathrm{e}}$ siècle pour ces statues monumentales de la Vierge que l'on vit fleurir sur les clochers des cathédrales $^{52}$, témoins d'une rechristianisation de l'espace urbain après la Révolution. C'est grâce à une généreuse donatrice anonyme que l'on redora la statue au début du siècle. Son don de six mille francs couvrit les frais de cette dorure à l'or en feuille,

50. Ibid., rapport fait au comité des inspecteurs généraux des édifices diocésains. Séance du 14 février 1857. Rapporteur : Léon Vaudoyer, inspecteur général.

51. Sculpteur né à Paris le 20 juin 1805, il entre à l'École des Beaux-Arts en 1828 ; il est élève de Lemaire. Il réalise en 1868 La Religion, modèle du marbre exécuté pour la chapelle du duc de Luynes à Dampierre, un Saint Étienne de pierre pour l'église Saint-Étienne-du-Mont (1868) et un Saint Maur et Saint Rémy pour l'église Sainte-Clotilde à Paris (1854). Émile Bellier de la Chavignerie, Louis Auvray, Dictionnaire général des artistes de l'École française depuis l'origine des arts du dessin jusqu'à nos jours, architectes, peintres, sculpteurs, graveurs et lithographes, Paris, H. Loones, 1882-1885, vol. 1, p. 593-594.

52. Michel Chevalier, La France des cathédrales du IV au XX siècle, op. cit., p. 367. 
au titre de 962, réalisée sous la direction de l'entrepreneur Bernard Laurent ${ }^{53}$. JeanLouis Pascal considérait qu'il était dommage d'avoir doré une statue de confection relativement médiocre : "On peut regretter que cette largesse ne s'adresse pas à une œuvre de plus grande valeur ; mais telle qu'elle est, elle domine à une distance considérable à la ronde et compte dans l'admirable paysage d'Avignon " ${ }^{54}$. Les remarques furent acerbes à l'encontre de cette statue dorée "ridicule qui ne déshonore pas seulement la cathédrale, mais toute la silhouette d'Avignon " 55 . André Hallays (1859-1930), critique d'art, trouvait que «cette image étincelante et obsédante, désastreux symbole du goût qui régna dans le clergé au XIX ${ }^{\mathrm{e}}$ siècle [...] déshonorait le site du rocher d'Avignon ${ }^{56}$."

\section{L'ouvre de Jean-Louis Pascal à l'intérieur de la cathédrale}

\section{Les vitraux}

En succédant à Eugène Danjoy, Jean-Louis Pascal hérite d'un édifice dont les vitraux sont en mauvais état. Ce sont tout d'abord les vitraux de la coupole 57 (ill. 3) située à vingt-cinq mètres du sol, qui coiffe le lanternon octogonal au-dessus de l'avant-dernière travée précédant le chœur. "Le lanterneau octogonal s'appuie sur des trompes en cul-de-four simplement ornées d'un enroulement. Chaque angle de l'octogone est habité par une colonnette ronde, cannelée, à chapiteau, à l'intérieur comme à l'extérieur. Huit fenêtres en plein cintre s'ouvrent sur les faces de ce piège à lumière pour l'abside et l'autel majeur " ${ }^{58}$. Jean-Louis Pascal s'occupe aussi des vitraux du chœur (ill. 8). Détériorés à la Révolution, et probablement remplacés par des verres blancs, ils étaient l'objet de demandes de crédits de la fabrique envers

53. Pour un coût de 5998 francs. Bernard Laurent, entrepreneur de maçonnerie, 38 rue du rempart du Rhône, Avignon. Arch. nat., F 19 7627, lettre de Jean-Louis Pascal au ministre des cultes, 21 août 1900. La statue avait déjà été dorée en 1859 par Michel Bent et en 1900, elle est dorée par L. Combe et Charles Raterino.

54. Ibid., lettre de Jean-Louis Pascal au ministre de la justice et des cultes, 11 mai 1900.

55. G. Pillement, Défense et Illustration d'Avignon, Paris, B. Grasset, 1945, p. 34-35; cité par Mgr Reyne, abbé Daniel Brehier, La Métropole de Notre-Dame des Doms, haut lieu de spiritualité d'art et d'histoire, op. cit., note 41, p. 154.

56. Cité par Mgr Reyne, Abbé Daniel Bréhier, La Métropole de Notre-Dame des Doms, haut lieu de spiritualité d'art et d'histoire, op. cit., note 41, p. 154.

57. Arch. nat., $F^{19} 7626$, lettre du 5 avril 1889 de Jean-Louis Pascal au ministre de la justice et des cultes " au sujet de la réfection des vitraux de la grande coupole de la cathédrale d'Avignon après de forts vents de mars 1889 ». Dans une lettre de Jean-Louis Pascal au ministre du 21 avril 1892, il écrit : "Quant à la réparation des vitraux, elle est de première nécessité et j’y insiste. Il y en a qui sont dangereux ", Arch. nat., F ${ }^{19}$ 7627. Une lettre de l'archevêché d'Avignon signée du vicaire général Redon, datée du 22 février 1896 demande encore "la réparation des vitraux en mauvais état de la métropole ", ibid. Un devis estimatif des réparations à effectuer à la cathédrale d'Avignon, de Jean-Louis Pascal au préfet du Vaucluse daté du $1^{\text {er }}$ décembre 1904 demande la réparation des vitraux de la grande coupole, ibid.

58. Mgr André Reyne, abbé Daniel Brehier, La Métropole de Notre-Dame des Doms, haut lieu de spiritualité d'art et d'histoire, op. cit., p. 252. 


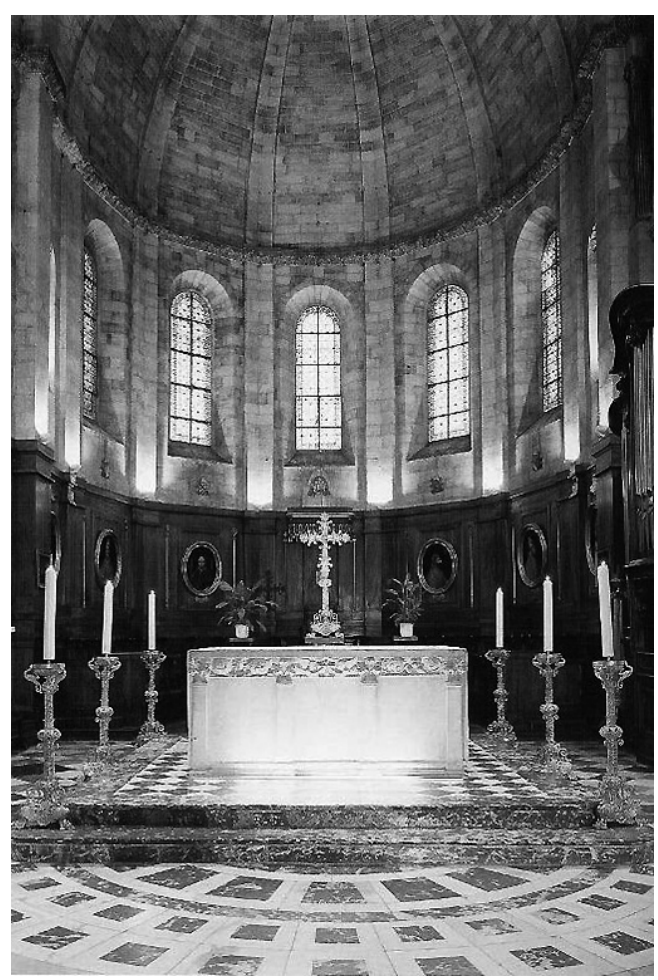

Ill. 8 : Le chœur de la basilique Notre-Dame des Doms et son mâtre-autel, XII ${ }^{\mathrm{e}}$ siècle. Les vitraux ont été réalisés en avril 1881 par le peintre verrier parisien Paul Charles Nicod. Les portraits des sept papes légitimes d'Avignon qui se détachent sur la boiserie dans des cadres ovales en bois doré ont été peints en 1869-1870 par Jean Garnier. Mgr André Reyne, abbé Daniel Brehier, La Métropole Notre-Dame des Doms, haut lieu de spiritualité, d'art et d'histoire, Lyon, Art et Tradition, s. d., p. 256.

l'État depuis le début du siècle. Un projet du maître verrier Étienne Thévenot de Clermont-Ferrand proposait, en septembre 1845, d'y représenter une Assomption et les saints évêques protecteurs de la cité, de part et d'autre ${ }^{59}$. En 1861, les cinq fenêtres du chœur sont légèrement modifiées par le maçon Pierre Discour, pour les harmoniser avec les ouvertures de la coupole. Mais la question des vitraux n'est pas réglée. Le 26 avril 1879, cinq mille francs sont prévus pour faire exécuter les verrières du chœur sur des dessins de Charles Michel Guilbert d'Anelle ${ }^{60}$ (1820-1889), peintre-verrier; on prévoit des vitraux à médaillons légendaires laissant passer le plus possible la lumière. Par mesure d'économie, on se contentera d'ouvrir la fenêtre

59. Ibid., p. 282.

60. Né à Paris, élève de Paul Delaroche, Horace Vernet et Adolphe Hervier. Il est protraitiste et peintre d'histoire. Il habite 5 rue Dorée à Avignon en 1885. Émile Bellier de la Chavignerie, Louis Auvray, Dictionnaire général des artistes de l'École française depuis l'origine des arts du dessin jusqu'à nos jours, op. cit., vol. 1, p. 722 . 
médiane, alors murée ${ }^{61}$. En avril 1881, on remplace enfin les menuiseries à vitres, et le peintre-verrier parisien Paul Charles Nicod ${ }^{62}$ exécute, à la demande de l'architecte diocésain, les vitraux de la coupole et ceux du chœur en s'inspirant de motifs décoratifs romans ${ }^{63}$. En 1897 , Jean-Louis Pascal note le mauvais état des anciennes verrières des chapelles latérales, endommagées par la violence des vents du nord et perméables à l'eau ; il faut les remanier en partie, les consolider et les compléter ; l'architecte demande le remplacement des anciennes menuiseries à vitres en mauvais état par des vitraux en grisaille avec bordure de couleur ${ }^{64}$. Pascal demande une somme de 3591,53 francs pour les réparer. Le peintre-verrier Arthur Bedoiseau, successeur de la maison Guilbert d'Anelle est choisi sur les conseils de l'architecte diocésain ${ }^{65}$.

\section{Le mobilier}

Les boiseries du chœur de la Métropole ${ }^{66}$, détruites à la Révolution, furent remplacées en 1824. Le dessin en fut donné par François Debret (1777-1850), l'architecte de la basilique de Saint-Denis. Il s'agissait de trente stalles en bois de noyer avec filets et ornements, croix et crosses, rosaces avec volutes sur leurs lambris. Sous le baldaquin accroché au fond du chœur, était installé un beau siège épiscopal aux accoudoirs ornés de têtes d'anges et surmonté des armoiries de Mgr de Mons ${ }^{67}$. En 1888, quand Jean-Louis Pascal arrive à Avignon, il constate que les boiseries, formant lambris sur une partie des murs de l'abside, sont en mauvais état. JeanLouis Pascal fait déposer les stalles, les bancs, les agenouilloirs, les marches et autres parties de menuiseries en bois dur ${ }^{68}$.

61. Arch. dép. du Vaucluse, 3V8, lettre de l'architecte diocésain Joseph Joffroy au préfet, 26 avril 1879.

62. Né à Paris, élève de P. Delaroche, il réalise le spécimen des vitraux pour Notre-Dame-de-la-Garde à Marseille (1859), des Anges portant les attributs de la Trinité, vitrail de 1869 pour l'église de SaintGervais à Paris, et une Apothéose de saint Gervais et saint Protais en lave émaillée pour le porche de l'église Saint-Gervais de Rouen (1880). Il habite 6 rue du Regard à Paris en 1885. Émile Bellier de la Chavignerie, Louis Auvray, Dictionnaire général des artistes de l'École française depuis l'origine des arts du dessin jusqu'à nos jours, architectes, peintres, sculpteurs, graveurs et lithographes, op. cit., vol. 2, p. 157.

63. Mgr André Reyne, abbé Daniel Brehier, La Métropole de Notre-Dame des Doms, haut lieu de spiritualité d'art et d'histoire, op. cit., p. 283.

64. Arch. nat., $\mathrm{F}^{19}$ 7627, devis estimatif des travaux de grosses réparations à exécuter en 1897, JeanLouis Pascal, 17 décembre 1896.

65. Arthur Bedoiseau, 48 rue de la Banasterie, Avignon. Arch. nat., F ${ }^{19} 7627$, soumissions pour la réparation des vitraux des chapelles latérales de la cathédrale d'Avignon, 26 novembre 1897.

66. Ces boiseries avaient été mises en place lors de l'agrandissement du chour au XVII siècle; dessinées par Pierre Mignard et sculptées par Esprit Grangier, elles comportaient un grand lambris composé de colonnettes et de pilastres d'ordre ionique, supporté par un stylobate posé sur les stalles elles-mêmes. Entre les pilastres étaient encastrés neuf grands médaillons avec les portraits des papes d'Avignon. Mgr André Reyne, abbé Daniel Brehier, La Métropole de Notre-Dame des Doms, haut lieu de spiritualité d'art et d'histoire, op. cit., p. 278.

67. Étienne de Maurel de Mons, archevêque d'Avignon de 1821 à 1830.

68. Arch. nat., $\mathrm{F}^{19}$ 7627, devis des travaux d'entretien à exécuter en 1902, Jean-Louis Pascal, 30 décembre 1901. 
Les portraits des sept papes légitimes d'Avignon qui se détachent actuellement sur la boiserie (ill. 8) dans des cadres ovales en bois doré rappellent ce qu'était autrefois le décor du chœur de la Métropole. Ils ont été peints en 1869-1870 par Jean Garnier dont l'atelier était situé place Saint-Pierre, et offerts à Notre-Dame des Doms par Napoléon III ${ }^{69}$.

\section{Les orgues}

La Métropole se dota en 1826 d'un orgue italien réalisé par le facteur lombard Piantanida qui passait pour posséder le secret d'un alliage de zinc, plomb et étain qui donnait aux tuyaux de ses instruments une admirable qualité de son ${ }^{70}$. En 1838, l'architecte départemental Renaux transfere l'orgue, alors placé au-dessus de la porte d'entrée, sur la tribune à gauche du sanctuaire. À cette occasion, un nouveau buffet est réalisé par le menuisier Brunet et doré par Michel Bent. Ce buffet présente un ordre corinthien, avec bases et consoles décorées de feuilles d'acanthes, faces ajourées ornées de lyres et d'enroulements végétaux que l'on retrouve sur l'entablement, alternativement avec des coquilles, sous une corniche à modillons. La façade se divise en deux mitres de treize tuyaux, encadrant une tourelle de cinq tuyaux, dont certains (dits tuyaux chanoines) sont muets ${ }^{71}$. Un très beau roi David jouant de la harpe surmonte le buffet. En 1861, pour pallier l'essoufflement de l'orgue doré, on ajoute dans le chœur un orgue d'accompagnement à tuyaux. C'est cet " orgue de commerce, très vilain de forme [...] instrument affreusement encombrant, présentant une grosse masse derrière le maitre-autel et empêchant ainsi toute direction orchestrale " ${ }^{72}$, que Jean-Louis Pascal propose de remplacer en 1902, à la demande de Mgr Sueur "soucieux de belles exécutions musicales " ${ }^{73}$. L'orgue à dix jeux et onze registres est réalisé, d'après les dessins de Jean-Louis Pascal, par le facteur d'orgues parisien Charles Mutin ${ }^{74}$ pour la somme de quinze mille francs ${ }^{75}$. Jean-Louis Pascal le place à droite du maître-autel, adossé à une paroi murale derrière laquelle monte un escalier conduisant à une dépendance de la sacristie :

«Dans la composition du petit buffet, j'avais à tenir compte de la forme et de la saillie de l'extrémité du balcon qui a transformé l'église romane sous Louis XIV, et de l'existence, dans l'arcade aveugle, d'un grand tableau faisant pendant à une œuvre analogue placée symétriquement sur la face opposée.

69. Les cadres coûtèrent 420 francs et les portraits, 700 francs. Archives du Chapitre, note sur les secours apportés par le gouvernement à Mgr l'Archevêque pour sa métropole, ainsi que les dépenses faites à cette occasion par la fabrique en 1868-1869 cité dans Mgr André Reyne, abbé Daniel Brehier, La Métropole de Notre-Dame des Doms, haut lieu de spiritualité d'art et d'histoire, op. cit., note 60 p. 280.

70. Ibid., p. 373.

71. Ibid., p. 378.

72. Arch. nat., $F^{19} 7627$, lettre de Jean-Louis Pascal au ministre de l'instruction publique et des cultes, 28 janvier 1902.

73. Ibid.

74. Charles Mutin, 15 avenue du Maine, Paris.

75. Arch. nat., $F^{19} 7627$, extrait du registre des délibérations de la fabrique de la métropole, diocèse d'Avignon, 9 février 1902. 
J'avais à me raccorder à une grande boiserie très peu moulurée qui fait le tour du chœur, à ne pas gêner en plan la circulation autour du maître-autel et à éviter le contact avec le balcon. Ces diverses difficultés m'ont amené à élever le moins possible le buffet, à enfoncer dans une petite niche l'instrumentaliste qui verra cependant aisément les co-exécutants dans le chœur et à placer la soufflerie derrière, sous l'escalier. Le petit problème n'était pas aisé et a dicté les formes employées ${ }^{76}$."

\section{La chapelle du Saint-Sacrement}

Construite en 1344 au nord de la cathédrale (ill. 2), elle était destinée à recevoir le tombeau du pape Benoît XII ${ }^{77}$ (Jacques Fournier (1285-1341), pape de 1334 à 1341).

La chapelle fut entièrement reprise au début du XIX ${ }^{\mathrm{e}}$ siècle, dans le but d'y présenter la Vierge commandée à James Pradier (1790-1852), en 1838, après l'épidémie de choléra ${ }^{78}$. Le projet fut abandonné et la chapelle primitivement dédiée à la sainte Vierge, titulaire de la métropole, le fut au "Corpus Christi » :

"Les murs furent reconstruits pour délimiter un sanctuaire à voûtes en plein cintre reposant sur quatre colonnes (le mur du fond à archivolte, reposant elle aussi sur colonnes formant retable) et une nef à deux travées en plein cintre, tombant sur colonnes engagées, sauf au-dessus de la grande grille latérale, à droite ${ }^{79}$."

On plaça un autel de marbre blanc à décor de strigiles (ill. 9), orné de consoles latérales, et un "marchepied en mosaïque de marbre", exécuté par le sculpteur Baussan $^{80}$.

En avril 1839, le serrurier Duval réalise une grille à hauteur d'appui placée dans une grande arcade en plein cintre faisant communiquer les deux premières chapelles au nord. Le sol fut pavé de marbre blanc et bleu turquin et les vitraux montés par le verrier Isnard ${ }^{81}$.

76. Ibid., lettre de Jean-Louis Pascal au ministre de l'instruction publique et des cultes, 28 janvier 1902.

77. Le tombeau en ayant été saccagé à la Révolution, Casimir Poitevin reconstitua un tombeau en 1831 sur le mur nord de la chapelle attenante dite "de l'archevêque Florès " ou "du Pardon ", à l'aide de pièces plus anciennes provenant notamment du tombeau du cardinal Jean de Cros, évêque de Preneste, décédé en 1383 et préalablement enterré auprès du pontife dans la chapelle du SaintSacrement. C'est un tombeau avec gisant sous enfeu.

78. Elle est actuellement dans la chapelle de Notre-Dame des Doms, ou chapelle de la Résurrection, troisième chapelle au sud de la cathédrale, ajoutée au XVII ${ }^{\mathrm{e}}$ siècle. Cette Vierge d'intercession fut présentée au Salon du Louvre en mars 1838 et critiquée pour le manque d'expression de son visage et l'abondance inutile des plis de sa robe.

79. Mgr Reyne, abbé Daniel Brehier, La Métropole de Notre-Dame des Doms, haut lieu de spiritualité d'art et d'histoire, op. cit., p. 304.

80. Arch. chap., Registre du bureau, fol. 3 v, 26 mars 1840, cité par Mgr Reyne, abbé Daniel Brehier, La Métropole de Notre-Dame des Doms, haut lieu de spiritualité d'art et d'histoire, op. cit., n. 16, p. 305.

81. Arch. chap., Registre du bureau, fol. 1, 28 avril 1839. Registre de fabrique, fol. $16 \mathrm{v}^{\mathrm{o}}$, commande du 13 août 1839, cité par Reyne, abbé Daniel Brehier, La Métropole de Notre-Dame des Doms, haut lieu de spiritualité d'art et d'histoire, op. cit., n. 17, p. 305. 


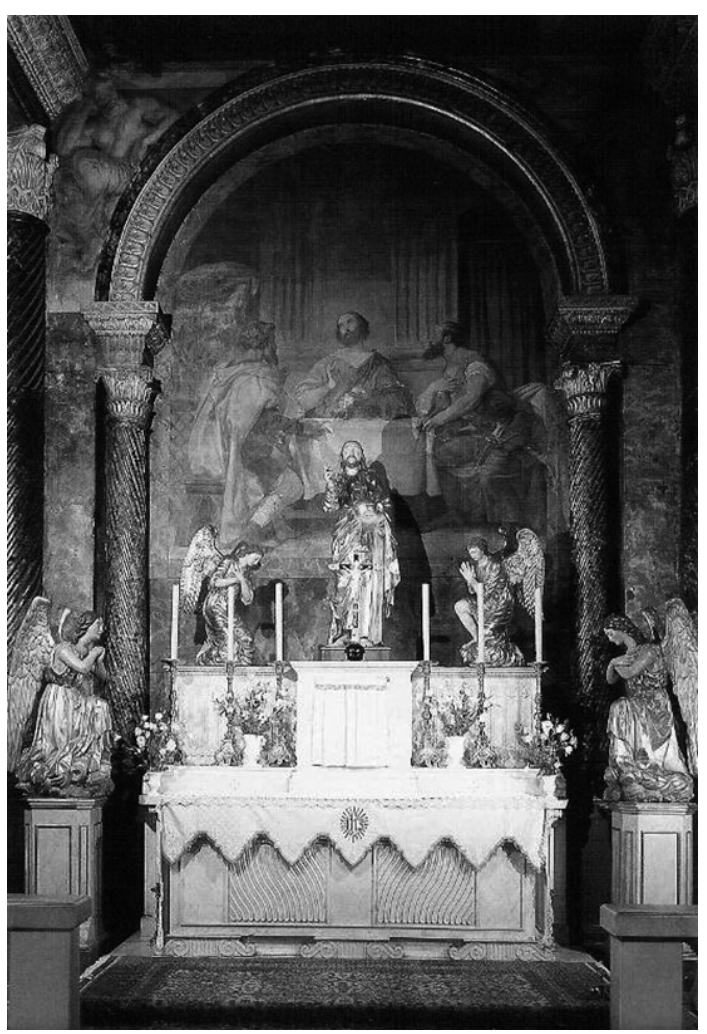

Ill. 9 : Chapelle du Saint-Sacrement de la basilique Notre-Dame des Doms, construite en 1344, appelée "chapelle des peintures", décorée de la fresque des Pélerins d'Emmaüs par Eugène Devéria en 1840. Mgr André Reyne, abbé Daniel Brehier, La Métropole Notre-Dame des Doms, haut lieu de spiritualité, d'art et d'histoire, Lyon, Art et Tradition, s. d., p. 256.

L'un des problèmes majeurs de cette chapelle située au nord de l'église était l'humidité, due aux mauvais écoulements des eaux pluviales et à leur infiltration dans les murs construits sur un rocher ne permettant aucune absorption. Pour y remédier, l'architecte Prosper Renaux abaissa le sol de la chapelle, couvrit en partie les murs d'une couche de goudron, établit une boiserie en pin du nord sur le soubassement des murs et passa les toitures (complètement refaites en 1827) à l'huile de noix.

Augustin Caristie (1783-1862) fit un rapport sur cette chapelle, encore appelée " chapelle des peintures ", devant le conseil des bâtiments civils ; il préconisait d'utiliser les moyens employés contre l'humidité à la coupole de l'église Sainte-Geneviève à Paris et au palais de la Bourse : "Il consiste à enduire les murs, lorsqu'ils sont en pierre de taille, comme à Sainte-Geneviève, du mélange de quatre cinquièmes d'huile de noix et d'un cinquième de cire vierge, appliqué bouillant sur les murs, puis à donner deux à trois couches de blanc de cérusé [mêlé] à [de] l'huile de noix, ou 
bien, si l'on doit peindre sur un enduit en plâtre, à donner, comme on l'a fait à la Bourse, une couche d'huile de lin bouillante puis deux à trois couches de blanc de cérusé avec la même huile " ${ }^{82}$. Le conseil des bâtiments civils fit observer "qu'un enduit en bitume ne serait pas une préparation convenable pour recevoir les peintures qui pourraient être altérées par le contact de cette matière ". En 1838, il fut décrété que "l'enduit au bitume minéral n'est nullement destiné à recevoir la peinture mais que son but est d'intercepter l'humidité du salpêtre ; il doit être recouvert par un bon enduit en chaux hydraulique du Teil appliqué en deux couches, et c'est sur ce double enduit bien lifté et refrotté au tampon que $M$. Eugène Devéria, chargé des peintures, appliquera à ses frais les couches d'huile et de cire vierge nécessaire pour assurer la bonne exécution et la durée de ses ouvrages " 83 .

Mgr Dupont ${ }^{84}$ avait pensé au peintre Eugène François Marie Joseph Devéria (1805-1865) pour décorer l'ensemble de la métropole. Peintre dans la mouvance d'Eugène Delacroix et Théodore Géricault (1791-1824), Devéria participe ici à ce renouveau de la peinture religieuse qui se produit sous la monarchie de Juillet ${ }^{85}$.

Le 21 juillet 1837, Célestin Dupont et Eugène Devéria signaient une convention par laquelle ce dernier s'engageait à décorer «les voûtes et murs de la métropole d'Avignon et des chapelles adjacentes "; seule la chapelle du Saint-Sacrement et une partie de celle attenante, dite "de Charlemagne ", seront décorées par le peintre, qui réalisait ainsi, selon le mot de Bruno Foucart, "la Sixtine mariale du romantisme ${ }^{86}$ :

"La chapelle de la Vierge dans l'église Notre-Dame des Doms à Avignon, est peut-être avec la chapelle des saints anges ${ }^{87}$ de Delacroix le manifeste le plus ambitieux de l'inspiration romantique dans un édifice religieux. Plus encore que la chapelle de Delorme ${ }^{88}$ à Saint-Gervais, elle doit être confrontée aux entreprises d'Orsel et de Périn ${ }^{89}$; à la chapelle nazaréenne et préraphaélite de ces derniers, il faut, pour bien entendre toutes les voix du siècle, joindre celle, vénitienne, d'Eugène Devéria ${ }^{90}$. "

82. Arch. nat., $\mathrm{F}^{19} 7625$, rapport d'Augustin Caristie devant le conseil des bâtiments civils au sujet des peintures à exécuter dans la "chapelle gothique " daté du 28 juin 1829 et adressé le 30 juin au ministre des affaires ecclésiastiques.

83. Ibid., rapport de l'architecte du département Renaux au préfet du Vaucluse, $1^{\text {er }}$ décembre 1838.

84. Jacques Marie Antoine Célestin Dupont, archevêque d'Avignon de 1835 à 1842.

85. Voir à ce sujet Bruno Foucart, Le Renouveau de la peinture religieuse en France (1800-1860), Paris, Athena, 1987, Jacques-Olivier Boudon, Paris, capitale religieuse sous le Second Empire, Paris, éd. du Cerf, 2001, p. 306-312, Michel Chevalier, La France des cathédrales, du IVe au XXe siècle, op. cit., p. 372-377.

86. Bruno Foucart, Le Renouveau de la peinture religieuse en France (1800-1860), op. cit., p. 243.

87. Première chapelle bas-côté droit de l'église Saint-Sulpice à Paris peinte par Delacroix entre 1847 et 1863 .

88. Il s'agit de la chapelle de la Vierge décorée par Pierre Claude François Delorme (1783-1859) à l'église Saint-Gervais à Paris.

89. Il s'agit de la chapelle des litanies de la Vierge décorée par les peintres de l'École lyonnaise Victor Orsel (1795-1850), chef de file des «nazaréens français », et Alphonse Périn (1798-1874), à l'église Notre-Dame-de-Lorette à Paris.

90. Bruno Foucart, Le Renouveau de la peinture religieuse en France (1800-1860), op. cit., p. 243. 
Le contrat prévoyait le début des travaux en mars 1838. Ce n'est qu'en septembre, après un voyage à Milan pour assister au couronnement de Ferdinand $1^{\text {er }}$ d'Autriche en tant que roi de Lombardie, qu'Eugène Devéria commence la décoration de la chapelle. Aidé du peintre ornemaniste Charles Alexis Apoil (1809-1864), et du maçon Laurent Gaget pour les enduits, Devéria poursuit ses travaux jusqu'au 29 octobre 1840, date à laquelle une importante inondation survenue à Avignon le force à s'interrompre ${ }^{91}$. C'est lors de cette première campagne de travaux qu'il décore l'ensemble de la chapelle du Saint-Sacrement à l'aide de la technique de la fresque $^{92}$ et de la cire sur enduit. Dans la convention passée entre Eugène Devéria et Mgr Dupont le 21 juillet 1837, on lisait en effet à l'article 2: "Le peintre se réserve d'exécuter ces peintures à l'huile, à la cire ou à la fresque, selon ce qu'il entendra et de manière à obtenir partout le meilleur effet possible ». Devéria demande une somme de soixante-quatre francs supplémentaires pour peindre les colonnes, corniches et autres parties d'architecture non comprises dans le devis initial de Mgr Dupont ${ }^{93}$.

Le programme initial définissait trois grandes directions thématiques: tandis que le chœur et la chapelle de la Vierge recevaient des sujets se rattachant tous à la vie terrestre ou céleste de la Vierge, l'entrée de l'église était vouée à l'évocation des débuts du christianisme et la nef à celle de la papauté avignonnaise, puisque devaient y figurer saint Pierre et les sept papes ayant résidé à Avignon ${ }^{94}$. Devéria prévoyait de décorer chaque tribune à l'aide de l'effigie à mi-corps d'un pape, dans un médaillon entouré de deux allégories ${ }^{95}$.

En définitive, une seule chapelle sera décorée ; la peinture dominant l'autel de la chapelle des peintures représente les disciples d'Emmaüs reconnaissant le Christ à la fraction du pain, au moment précis où il va disparaître (ill. 9). Peinte en juin 1840, alors que la chapelle de la Vierge a repris son ancienne dénomination de chapelle du Saint-Sacrement, le pèlerin de gauche pourrait être un autoportrait du

91. Durant cette période, le peintre, que son contrat laissait pratiquement libre les mois d'hiver, va également se consacrer à quantité de commandes annexes dont témoignent une grande composition peinte pour le couvent de la Visitation à Avignon (L'Apparition de notre Seigneur à la bienheureuse Marie Alacoque, Sorgues, monastère de la Visitation) ainsi qu'un vaste ensemble décoratif retraçant l'histoire de Psyché réalisé pour la famille Sabatier et qui prouve la présence de Devéria à Avignon en 1840 (Château d'Espeyran, Saint-Gilles du Gard). Rodolphe Rapetti, "Eugène Devéria et le décor de la chapelle de la Vierge à la cathédrale d'Avignon ", Bulletin de la Société de l'Histoire de l'Art français, 1984, p. 207-228.

92. Seules les peintures des Pélerins d'Emmaüs (au-dessus de l'autel) et probablement la Regina Angelorum seront réalisées selon cette technique. Regina Angelorum et Regina Martyrum, associée en diptyque avec un Martyr de saint Laurent, se situent dans la chapelle en communication avec celle du Saint-Sacrement, inachevée, dite de Charlemagne.

93. Mgr Reyne, abbé Daniel Brehier, La Métropole de Notre-Dame des Doms, haut lieu de spiritualité d'art et d'histoire, op. cit., p. 307.

94. Cette partie non réalisée du projet est connue par quinze dessins qui se trouvent au musée Calvet à Avignon.

95. Rodolphe Rapetti, "Eugène Devéria et le décor de la chapelle de la Vierge à la cathédrale d'Avignon ", op. cit., p. 214. 
peintre et celui de droite, son aide ornemaniste. Sur l'arc triomphal, Devéria représente le roi David chantant les psaumes en s'accompagnant de sa harpe (la jeune fille au premier plan, à droite de la composition, serait un portrait de Marie Devéria, la fille du peintre) ; "Cette figuration [...] fut interprétée par un journal de l'époque comme faisant allusion à la métaphore qui, dans les Litanies, [décorant, elles, les compartiments des voûtes] désigne la Vierge sous le vocable de "tour de David". " ${ }^{66}$

Sur la voûte du chœur surplombant l'autel sont représentées les vertus théologales : Foi, Espérance et Charité. À droite et à gauche de l'autel ont été peintes en août 1839 la Visitation et la Présentation au temple, peut-être un rappel historique de l'institution de ces deux fêtes par les papes d'Avignon ${ }^{97}$. Pour Bruno Foucart, " à la fois chapelle du Saint-Sacrement et de la Vierge, la chapelle de Devéria associe donc directement le Christ et la Vierge, non dans les épisodes attendus de la Passion, mais dans la célébration conjuguée de l'Incarnation et de la Transsubstantiation. " ${ }^{98}$

Sur le mur proche de la nef, de part et d'autre de la grille d'accès à la chapelle, deux invocations des litanies: Mater admirabilis et Mater purissima, sont datées de 1840 ; au-dessous un décor de faux marbre et dans le registre supérieur, Jérémie et Isaïe, Daniel et Ezéchiel auraient été exécutés en octobre 1838. Pour Rodolphe Rapetti, la présence des quatre grands prophètes se justifie à double titre : "d'une part, la Vierge est invoquée dans le texte des Litanies en tant que reine des prophètes (Regina Prophetarum) et d'autre part, rappelons que certaines prophéties d'Isaïe et d'Ezéchiel ont été comprises comme annonçant l'Incarnation ${ }^{99}$. "

Dans les compartiments des voûtes, les invocations des litanies de la Vierge se déroulent sur des phylactères, des couples d'anges portant les attributs mariaux : rose et tour d'ivoire, étoile, miroir et vase, phylactère portant en inscription l'" Ave Maria »; enfin deux grands anges portent l'Arche d'alliance sur le mur de l'arc du fond de la chapelle.

Sur le mur nord, au-dessous des fenêtres, dans un décor de faux marbre vert antique, on distingue les cœurs de Jésus et Marie. Rodolphe Rapetti pense que le thème des "Litanies de la Vierge " fut suggéré à Devéria par le décor de la chapelle de la Vierge commencée dès 1836 par Victor Orsel à Notre-Dame-de-Lorette à Paris, décor que Devéria ne pouvait ignorer puisqu'il réalisa deux tableaux pour la chapelle Sainte-Geneviève de cette même église ${ }^{100}$.

Atteint d'une maladie pulmonaire, Devéria s'interrompt ; au printemps 1841 il se soigne aux Eaux-Bonnes puis s'installe à Pau à partir de 1842. Il se convertit au protestantisme en 1843 .

96. Ibid., p. 215.

97. Mgr Reyne, abbé Daniel Brehier, La Métropole de Notre-Dame des Doms, haut lieu de spiritualité d'art et d'histoire, op. cit., p. 307.

98. Bruno Foucart, Le Renouveau de la peinture religieuse en France (1800-1860), op. cit., p. 243.

99. Rodolphe Rapetti, "Eugène Devéria et le décor de la chapelle de la Vierge à la cathédrale d'Avignon ", op. cit., p. 215.

100. Ibid., p. 215. Il s'agit de Sainte Geneviève rendant la vue à sa mère et L'Apothéose de sainte Geneviève à Paris, 1835. 
Une deuxième campagne de travaux débute en 1848: "Je compte commencer demain, écrivait [Devéria] dans son journal, à la date du 19 juin 1848, un tableau de grandes proportions, de ceux que je dois à l'archevêque de Bourges ${ }^{101}$ ". La chapelle dite " de Charlemagne " était restée plusieurs années encombrée d'échafaudages et en 1845 , le conseil de fabrique avait demandé au peintre s'il consentait à reprendre ses travaux. Devéria proposa alors de remplacer les fresques projetées par deux grands tableaux à l'huile et deux grisailles, ce qui présentait pour le peintre l'avantage de pouvoir exécuter les tableaux à $\mathrm{Pau}^{102}$. Il fit parvenir à Avignon entre 1851 et 1856 quatre grandes peintures à l'huile : La Présentation à la Vierge ${ }^{103}$, L'Adoration des bergers ${ }^{104}$, Le Repos pendant la fuite en Égypte ${ }^{105}$ et Le Reniement de saint Pierre ${ }^{106}$.

Durant l'été 1856, on lui demanda de revenir à Avignon pour restaurer une partie de ses œuvres dégradées par l'humidité. Malgré le décès de sa fille Marie qui survint peu de temps après, à Pau, il regagna la cité des Papes où il séjourna de janvier à mars $1857^{107}$.

En 1891, Jean-Louis Pascal souhaite réaliser pour la chapelle du Saint-Sacrement un appui de communion en fer forgé qu'il souhaite doré ; il demande donc des crédits au ministre de l'instruction publique et des cultes :

" Je suis en pourparlers pour une proposition de réparation d'un appui de communion en marbre dans la chapelle dite des peintures, agrandie du temps de Louis-Philippe et décorée par Devéria. Des armatures en fer, des goujons oxydés au contact de l'humidité des sols, ont fait éclater le marbre partout, et cette balustrade est à refaire dans une grande proportion. Les deux tablettes en sont cassées ainsi que les deux montants de la porte composée aussi de balustres dans un cadre de marbre ; [...] Or M. l'archevêque d'Avignon avait déjà fait savoir à mon prédécesseur M. Danjoy, qu’un généreux donateur avait mis à sa disposition une somme de 1200 francs si on voulait substituer à la balustrade en marbre un appui de communion en fer forgé » ${ }^{108}$.

Pascal demande donc au ministre une somme de 1200 francs conformément au principe d'aide de l'État s'élevant à la hauteur de celle obtenue de la fabrique ou

101. Jacques Marie Antoine Célestin Dupont, archevêque d'Avigon de 1835 à 1842 devient archevêque de Bourges de 1842 à 1859.

102. Maximilien Gauthier, Achille et Eugène Devéria, Paris, H. Floury, 1925, p. 133.

103. La toile mesure $3,84 \mathrm{~m}(\mathrm{H})$ sur $2,75 \mathrm{~m}(\mathrm{~L})$.

104. La toile mesure $3,84 \mathrm{~m}(\mathrm{H})$ sur $2,34 \mathrm{~m}(\mathrm{~L})$.

105. La toile mesure $1,84 \mathrm{~m}(\mathrm{H})$ sur $2,30 \mathrm{~m}(\mathrm{~L})$.

106. La toile mesure $3 \mathrm{~m}(\mathrm{H})$ sur $2,30 \mathrm{~m}(\mathrm{~L})$.

107. David Ojalvo, Eugène Devéria (Paris 1805 - Pau 1865), Musée des Beaux-Arts de Pau, exposition 29 octobre - 31 décembre 1965, 61 p.

108. Arch. nat., $\mathrm{F}^{19} 7627$, lettre de Pascal du 27 mars 1891 au ministre de l'instruction publique et des cultes. 
de l'évêché. Le devis de Pascal pour le remplacement de l'ancienne balustrade de marbre blanc par un appui de communion en fer forgé s'élève à 2158,86 francs ${ }^{109}$. La soumission de Noël Biret, entrepreneur de travaux de serrurerie d'art à Avignon est approuvée le 22 octobre 1891, pour un montant de 1530 francs. Pascal trouva que la grille réalisée témoignait $\mathrm{d}^{\prime}$ " un vrai talent professionnel » :

"L'appui de communion exécuté par un très habile serrurier d'Avignon que j'avais eu l'honneur de vous signaler, Biret, a donné pleine satisfaction. Il est en place dans la chapelle des peintures et j'ai à donner des instructions pour le peindre. Or la meilleure solution, étant donné le cadre et l'entourage, serait de dorer cette grille pour obtenir l'équivalent de l'éclat que donnait la balustrade en marbre blanc ${ }^{110}$."

Le directeur des cultes refusa néanmoins de dorer la grille, les crédits dont il disposait étant destinés à l'entretien et à la conservation des édifices diocésains et non aux travaux purement décoratifs ${ }^{111}$.

En 1865, quelques lignes de Théophile Gauthier dans Le Moniteur, témoignent de l'état des peintures de Devéria :

"Exécutées sur un enduit trop frais, sous des voûtes traversées par les infiltrations pluviales, ces peintures, à peine achevées, avaient déjà souffert d'altérations fâcheuses; de larges plaques se détachaient çà et là ; mais ce qui en restait brillait par un coloris si frais, si gai que la vieille et sainte église était illuminée. [...] On y reconnaissait encore les tons de la palette vénitienne qui, avant la révolution de juillet, avait fait saluer Devéria un des princes de la couleur ${ }^{112}$."

En 1900, Pascal alerte l'administration des Beaux-Arts sur l'état de conservation de la fresque de Devéria, Les Pélerins d'Emmaüs qui domine l'autel de la chapelle de l'Eucharistie. En outre, cette fresque serait, selon Pascal, masquée en partie par une statue "peu artistique " de la Vierge, dominant l'autel, et par des tentures de velours rouge $^{113}$. La couverture de la chapelle fut reprise en 1909. En 1912, Pascal fait un état des lieux de l'état des peintures de la chapelle et dresse un devis de restauration. Les peintures seront nettoyées à la mie de pain, consolidées au silicate

109. Arch. dép. du Vaucluse, 3V8, dossier : réparation de la balustrade de la chapelle " des peintures ", 1891-1892.

110. Arch. nat., $\mathrm{F}^{19} 7627$, lettre du 19 mars 1892 de Pascal au directeur des cultes.

111. Ibid., lettre du 26 mars 1892 du directeur des cultes à Pascal.

112. Cet article du Moniteur du 13 février 1865 est cité par Maximilien Gauthier, Achille et Eugène Devéria, op. cit., p. 133-134.

113. Arch. nat., $\mathrm{F}^{19}$ 7627, lettre du 24 mars 1900 du directeur des Beaux-Arts Henri Roujon au président du conseil, ministre de l'intérieur et des cultes. Depuis, la statue de la Vierge a été remplacée par une statue en bois doré du Christ Sauveur du monde datant du XVII siècle, provenant de l'entrée de la communauté des sœurs de l'hôpital Sainte-Marthe. Il est entouré de quatre anges en bois doré (ill. 9). Mgr Reyne, abbé Daniel Brehier, La Métropole de Notre-Dame des Doms, haut lieu de spiritualité d'art et d'histoire, op. cit., p. 309. 
de potasse et refixées à la gomme-laque et à la paraffine par Louis Joseph Yperman (1856-1935). Pascal remplace les vitraux de deux fenêtres de la chapelle.

L'année suivante, Jean-Louis Pascal réalise des réparations urgentes au beffroi et à la suspension des cloches de la grande tour, la consolidation de la balustrade en marbre formant appui de communion dans la grande nef et des raccords de pavages ${ }^{114}$. En 1919, Pascal démolit le vieil enduit, mortier et ciment, craquelé et soufflé de la voûte de la grande nef qui menaçait de s'écrouler. Le goudron appliqué sur la pierre est gratté et on repique à $0,02 \mathrm{~m}$ de profondeur de toute la surface à l'intrados pour obtenir un parement solide et régulier ${ }^{115}$.

114. Arch. dép. du Vaucluse, 4T 32, devis de Jean-Louis Pascal sur les travaux à exécuter en vue de la conservation de la cathédrale d'Avignon (4 353,75 fr.), 20 janvier 1913.

115. Ibid., devis de Jean-Louis Pascal sur les travaux à exécuter en vue de réparations urgentes à la voûte de la grande nef (15935,53 fr.), 8 mai 1919. 
